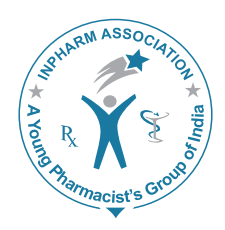

\title{
JVP
}

\section{Novel multi granules controlled release tablets of milnacipran: Design with simplex lattice, in vitro characterization and pharmacokinetic predictions}

\author{
Gautam Singhvi*, Niyati Parmar, Nirav Patel, Ranendra Narayan Saha
}

Department of Pharmacy, Birla Institute of Technology and Science, Rajasthan, India

\begin{abstract}
Aim: Milnacipran is well used drug for the treatment of depression and fibromyalgia. Its short elimination half-life, frequent dosing and associated side effects cause lack of patient compliance and discontinuation of present therapy. To overcome such problems, the aim of the present study was to design a novel multi granules based controlled release (CR) formulation with simplex lattice technique and study the various formulation variables. Materials and Methods: Hydrophilic polymeric and hydrophobic wax granules were prepared separately, and various formulations were designed with different proportion of these granules. Results: As the proportion of hydrophobic granules in formulation increased from $0 \%$ to $100 \%$, the mean dissolution time, time for $50 \%$ and $80 \%$ drug release extended from 4.88-8.95 h; 3.11-9.11 h and 10.51-20.72 h, respectively. All the formulations were following first-order release kinetic. Results of formulation variables indicated that viscosity of the polymer, hardness of tablets and agitation speed can significantly influence the drug release from formulations and no significant effect observed for $\mathrm{pH}$ of dissolution media. In vitro human plasma concentrations were predicted from in vitro release data using convolution method. Conclusion: Novel multi granule-based CR tablet formulations of milnacipran hydrochloride were designed and evaluated for its in vitro release.
\end{abstract}

Key words: Controlled release, convolution, milnacipran, multi granules, simplex lattice

\section{INTRODUCTION}

Milnacipran hydrochloride (MIL) is well used drug and a selective serotonin and norepinephrine reuptake inhibitor. MIL has been approved since 1997 for treatment of

\begin{tabular}{|c|c|}
\hline \multicolumn{2}{|c|}{ Access this article online } \\
\hline Journal Sponsor & \multirow[b]{2}{*}{$\begin{array}{l}\text { Website: } \\
\text { www.jyoungpharm.org }\end{array}$} \\
\hline \multirow{2}{*}{ www.phcog net } & \\
\hline & $\begin{array}{l}\text { DOI: } \\
\text { 10.5530/jyp.2014.3.5 }\end{array}$ \\
\hline
\end{tabular}

depression and also approved in January 2009 for treatment of fibromyalgia. MIL is a candidate of biopharmaceutical classification system Class I, having high solubility and high permeability. ${ }^{1} \mathrm{MIL}$ is commercially available as immediate release (IR) formulations in the form of tablets and capsules with dose of 25-100 mg. Its short elimination half-life (6-8 h), frequent dosing requirement (2-4 times) and the number of associated side-effects such as nausea, vomiting cause lack of patient compliance, which led to discontinuation problem. ${ }^{2,3}$

Thus, there is an opportunity to formulate a controlled release (CR) tablet of MIL which will reduce the frequency

*Address for correspondence:

Mr. Gautam Singhvi, Department of Pharmacy, Birla Institute of Technology and Science, Rajasthan - 333 031, India.

E-mail: singhvigautam@gmail.com 
of dosing and lower the incidence and intensity of side effects to get patient compliance with improved therapeutic level for the treatment of depression and fibromyalgia.

Very few publications are reported on CR formulation of MIL. Parejiya et al., worked on "Tab in Tab" type CR formulation and also formulated a CR osmotic pump tablets of MIL. ${ }^{1}$ Above reported approaches for CR formulation of MIL are tedious, costly and various critical process parameters are involved. Singhvi et al., worked on design and characterization of cost effective hydrophilic matrix tablets of MIL using hydroxypropyl methylcellulose (HPMC). ${ }^{4}$ Some literature revealed that multi granules CR formulations are better in release control than conventional matrix of single granules. ${ }^{5} \mathrm{It}$ is also reported that a combination of hydrophilic and hydrophobic polymers in a matrix can better control the drug release than alone hydrophilic polymer for prolong time. ${ }^{6}$ Hydrophilic polymers have the advantage of rapid hydration and formation of viscous gel layer to restrict the drug percolation, ${ }^{7,8}$ whereas hydrophobic polymers not only act as water repellent surface, but also provide several advantages, ranging from good stability at varying $\mathrm{pH}$ values and moisture levels to well-established safe applications. ${ }^{9}$ Thus, to combine the advantages of both hydrophilic and hydrophobic retardant in single dosage form, combination of both types of granules in a compact mass can be excellent to extend the drug release for sufficient time period at low concentration of polymers. ${ }^{10}$

Therefore, in the present work, a novel, simple, economic and reproducible multi granules based CR tablet formulation was designed using a combination of hydrophilic and hydrophobic granules. Simplex lattice design of optimization technique was applied for formulation design to minimize the formulation trials. The effect of formulation variables like polymer proportion, viscosity of hydrophilic polymer, compression force, agitation speed and $\mathrm{pH}$ of dissolution medium on in vitro release characteristics were also studied with various dissolution parameters. Moreover, pharmacokinetic (PK) properties including plasma profiles of selected formulation were predicted using numerical convolution method to evaluate the suitability of the designed drug delivery system for its practical application in humans.

\section{MATERIALS AND METHODS}

\section{Materials}

MIL was obtained as gift sample from Torrent Pharmaceutical Limited, Ahmadabad, India. All other chemicals and reagents used were of pharmaceutical or analytical grade.

\section{Analytical method}

An in-house developed and validated ultraviolet (UV) spectrophotometric method on UV-VIS-NIR Spectrophotometer (V-570, Jasco, Tokyo, Japan), was used for the estimation of MIL in formulations, in vitro release samples and for quality control testing. ${ }^{11}$

\section{Drug excipients compatibility studies}

Stability of MIL in presence of excipients like HPMC, di-calcium phosphate (DCP), paraffin wax, stearic acid, polyvinyl pyrrolidone (PVP) K-30, talc and magnesium stearate was studied with differential scanning calorimetry (DSC) and Fourier transform infrared (FTIR) spectroscopic (Shimadzu, Japan). All samples were stored at accelerated $\left(40 \pm 2^{\circ} \mathrm{C} / 75 \pm 5 \%\right.$ relative humanity $\left.[\mathrm{RH}]\right)$ and ambient $\left(25 \pm 2^{\circ} \mathrm{C}\right.$ and $\left.60 \pm 5 \% \mathrm{RH}\right)$ conditions protected from light up to 6 months and DSC and FTIR studies were repeated.

\section{Preparation of controlled-release tablets}

CR tablets of MIL were formulated with various proportions of hydrophilic polymer granules and hydrophobic wax granules. Both the granules were prepared separately as given below with composition as given in Table 1.

\section{Preparation of hydrophilic polymer granules}

Hydrophilic granules were prepared by wet granulation method. Drug, HPMC 100K and DCP were granulated with PVP K-30 using isopropyl alcohol as granulating agent. The mass was dried and sieved through 16 mesh.

Table 1: Formulation component of multi granules based controlled release tablets of milnacipran

\begin{tabular}{lcc}
\hline $\begin{array}{l}\text { Ingredients } \\
(\mathbf{m g})\end{array}$ & $\begin{array}{c}\text { Hydrophilic } \\
\text { granules part } \\
\text { Part A (mg) }\end{array}$ & $\begin{array}{c}\text { Hydrophobic } \\
\text { granules part } \\
\text { Part B (mg) }\end{array}$ \\
\hline Drug & 100 & 100 \\
HPMC 100K & 100 & 100 \\
\hline DCP & 100 & 60 \\
Stearic acid & & 60 \\
\hline Paraffin wax & Fraction of part A & Fraction of part B \\
\hline Batch no. & 100 & 0 \\
\hline F-1 & 70 & 30 \\
\hline F-2 & 50 & 50 \\
\hline F-3 & 30 & 70 \\
\hline F-4 & 0 & 100 \\
\hline F-5 & & \\
\hline
\end{tabular}

HPMC: Hydroxy propyl methylcellulose, DCP: Dibasic calcium phosphate 
Preparation of hydrophobic wax granules

Hydrophobic wax granules were prepared by melting stearic acid and paraffin wax at $80-85^{\circ} \mathrm{C}$ in a water bath. Uniform mixture of drug and DCP was added to molten wax with continuous agitation. The molten mass was allowed to cool at room temperature. The congealed solid mass was then sieved through 16 mesh.

The above hydrophilic polymer granules and hydrophobic wax granules were mixed in different proportions as per study design. The final granules were blended with talc $(3 \% \mathrm{w} / \mathrm{w})$ and lubricated with magnesium stearate $(3 \% \mathrm{w} / \mathrm{w})$. These lubricated granules were compressed on 16-station rotary tableting machine (CMB3-16, Cad Mach, Ahmadabad, India).

\section{Formulation design with simplex lattice optimization technique}

In order to design the best formulation, use a trial and error approach is not an effective way. The simplex lattice or mixture designs technique was applied for designing the various formulations. In simplex lattice, given equation is used for design the formulations and predict the responses. ${ }^{12}$

$\mathrm{Y}=\beta_{1}(\mathrm{~A})+\beta_{2}(\mathrm{~B})+\beta_{12}(\mathrm{~A})(\mathrm{B})$

In the proposed work " $\mathrm{A}$ " is hydrophilic granules part and " $\mathrm{B}$ " is hydrophobic granules part. Response "Y" is dissolution parameters like $\mathrm{T} 50 \%, \mathrm{~T} 80 \%$ and mean dissolution time (MDT).

$\beta_{1}=$ response at proportion of " $\mathrm{A}$ " is $100 \%, \beta_{2}=$ response at proportion of " $\mathrm{B}$ " is $100 \%$ and $\beta_{12}=4$ (response at proportion of " $\mathrm{A}$ " and " $\mathrm{B}$ " is $50-50 \%$ ) -2 (sum of response of "A" and "B" at $100 \%$ ).

For experimental design, three formulations (i) tablets with $100 \%$ hydrophilic granules (F-1), (ii) tablets with $50 \%$ hydrophilic $+50 \%$ hydrophobic granules (F-3) and (iii) tablets with $100 \%$ hydrophobic granules (F-5) were formulated. Then simplex lattice equation was derived for each response using the experimental values of above formulations. Two check point formulations F-2 (A 70\% and B 30\%) and F-4 (A 30\% and B 70\%) were formulated and characterize for all in vitro dissolution parameters. Formulation F-2 and F-4 were formulated and characterized for all in vitro dissolution parameters and responses were also predicted using simplex lattice equations. Differences between predicted and observed values were tested statistically using one-way analysis of variance (ANOVA).${ }^{12}$ Formulation nomenclature was given on the basis of their composition after complete study as given in Table 1.

\section{Physical characterization of the designed tablets}

The weight variation, crushing strength, friability and content uniformity of developed formulations were determined as per standard procedure given in United States Pharmacopeia (USP) ${ }^{13}$ using electronic balance (Type ER182A, Afcoset, Mumbai, India), Monsanto hardness tester (MHT20, Campbell Electronics, Mumbai, India), friability tester (FTA-20, Campbell Electronics, Mumbai, India) and UV-spectroscopic respectively.

\section{Dissolution methodology}

Dissolution study of all the tablets were performed with USP dissolution testing apparatus Type II Paddle (TDT$08 \mathrm{~L}$, Electro Lab., Mumbai, India) in $900 \mathrm{~mL}$ of $0.1 \mathrm{~N} \mathrm{HCl}$ $(\mathrm{pH} 1.2)$ dissolution medium, at $50 \mathrm{rpm}$ and $37 \pm 0.5^{\circ} \mathrm{C}$. At predetermined time point $10 \mathrm{~mL}$ of the sample was withdrawn and analyzed with developed UV-visible method. Percentage cumulative drug release was calculated for data analysis.

\section{In vitro drug release kinetic and mechanism}

Various in vitro release kinetic models like zero order, first order, Higuchi and Korsmeyer-Peppas model ${ }^{14,15}$ were applied in present study. The drug release from all the formulation were also compared with model independent dissolution parameters like MDT, time of $50 \%(\mathrm{~T} 50 \%)$ and $80 \%(\mathrm{~T} 80 \%)$ drug release. ${ }^{14,15}$ The similarities between two in vitro dissolution profiles were also assessed by other pair wise model independent procedures such as difference factor $\left(f_{1}\right)$ and similarity factor $\left(f_{2}\right) \cdot{ }^{15}$

\section{Study of formulation variables}

Formulation with equal proportion of hydrophilic and hydrophobic granules (F-3) was selected for study the effect of formulation variables like polymer proportion, viscosity of polymer, compression force, agitation speed and $\mathrm{pH}$ of dissolution medium on in vitro release.

\section{Prediction of human in vitro profile of selected formulation}

In vitro plasma profile and various $\mathrm{PK}$ parameters of selected multi granules CR tablets and IR formulation of 
MIL were predicted with numerical convolution method using in vitro release data. Reported PK parameters like elimination rate constant, volume of distribution and oral bioavailability of MIL were used to for convolution method to get the predicted plasma drug levels at various time points. This predicted in vitro parameters will help in screening of desire formulation for in vitro studies in animal and human. This PK prediction will help to decide the optimized formulation prior to animal study. Thus, this prediction is not only minimize the number of in vitro studies but also reduces the time and cost of formulation design. ${ }^{16}$ Peak plasma concentration $\left(\mathrm{C}_{\max }\right)$ and time of its occurrence $\left(\mathrm{T}_{\max }\right)$, biological half-life, mean residence time (MRT) and area under the curve (AUC) of both IR and CR tablets were determined using WinNonLin-Professional 2.1 (Pharsight Corporation, USA). Predicted PK parameters of IR formulation were also compared with reported clinical in vitro parameters of commercial IR formulations for validation of convolution method.

\section{Statistical analysis}

One-way ANOVA was used to determine statistically significant differences between observed and predicted response of formulations designed with simplex lattice. ANOVA was also used between PK parameters of IR and CR tablets. Results with $P<0.05$ were considered as statistically significant $(\alpha=0.05) .{ }^{12}$

\section{RESULTS AND DISCUSSION}

\section{Drug excipients compatibility studies}

Presence of all the peaks of MIL in all spectrums indicates the stable nature of MIL in the solid admixtures. The DSC thermo grams of pure MIL showed a sharp melting endoderm at $178^{\circ} \mathrm{C}$ with a normalized energy of $47.55 \mathrm{~J} / \mathrm{g}$. The thermo grams of solid admixtures of MIL with various excipients, characterized after 6 months of storage, also had shown similar peak at $178^{\circ} \mathrm{C}$ with almost the same normalized energy, indicating that MIL is unaffected in the presence of various excipients used in the preparation of CR tablets formulations.

\section{Physical characterization of the designed tablets}

The prepared tablets were subjected to all the quality control tests as shown in Table 2. The physical appearance, weight variation, tablet hardness, friability and content uniformity of all tablet formulations were found to be satisfactory and within the official pharmacopoeial limits.

\section{Formulations designs with optimization technique}

Simplex lattice equation was derived for each response using experimental values of F-1, F-3 and F-5. Simplex lattice equations for dissolution parameters are given below:

$$
\begin{aligned}
& \mathrm{T} 50 \%=\mathrm{Y}_{1}=3.58(\mathrm{~A})+8.79(\mathrm{~B})-3.3(\mathrm{~A})(\mathrm{B}) \\
& \mathrm{T} 80 \%=\mathrm{Y}_{2}=8.32(\mathrm{~A})+20.42(\mathrm{~B})-7.72(\mathrm{~A})(\mathrm{B}) \\
& \mathrm{MDT}=\mathrm{Y}_{3}=4.88(\mathrm{~A})+8.95(\mathrm{~B})+0.42(\mathrm{~A})(\mathrm{B})
\end{aligned}
$$

Predicted and observed responses of intermediate formulations (F-2 and F-4) are shown in Table 3. One-way ANOVA was applied on predicted and observed values. The calculated $F$ value was found lesser than critical $F$ value at $P<0.05$, indicating that predicted and observed values are not significantly different. Results of simplex lattice design in present study indicated that such optimization study can be used for formulation design to get the desire results and process optimization with minimum number of trials.

\section{In vitro drug release study}

Various mathematical models were used to study the release kinetic and mechanism of drug release from multi granules CR tablets. Korsmeyer-Peppas model was found to best fit $\left(r^{2}>0.9869\right)$ for all the formulations F-1 to F-5.

Various formulation variables were studied as follows:

\section{Effect of polymer proportion on drug release}

In vitro release profiles of all the formulations as shown in Figure 1 indicated that initial release for first $2 \mathrm{~h}$ varied between $22 \%$ and $38 \%$ depending on hydrophilicwax granules proportion. The release rate constant of Korsmeyer-Peppas model were found to be $32.20 \mathrm{~h}^{-0.386}$, $26.66 \mathrm{~h}^{-0.441}, 21.80 \mathrm{~h}^{-0.496}, 17.64 \mathrm{~h}^{-0.545}$ and $14.14 \mathrm{~h}^{-0.572}$ for F-1 to F-5 respectively. The release exponent " $n$ " values of Korsmeyer-Peppas model for formulations F-1 and F-2 was found to be 0.39 and 0.44 indicating that the release mechanism was Fickian diffusion. This may be due to proportion of hydrophilic polymeric granules (70-100\%) is more in these formulations. The release exponent " $n$ " values for formulations F-3 to F-5 indicated non-Fickian or anomalous release $(0.45<n<0.89)$ which indicated that drug release from these CR tablets was dependent on both drug diffusion as well as polymer relaxation. The values of $n$ increased (0.39-0.57) as the proportion of hydrophobic wax granules was increased in tablet (F-1 to F-5). Hence, it can be inferred that the influence of polymer relaxation/ 
Table 2: Physical characterizations of multi granules based controlled release tablets of milnacipran

\begin{tabular}{lcccrr}
\hline Formulations & Weight variation (\%) & Thickness $(\mathbf{m m})$ & Hardness $\left(\mathbf{k g} / \mathbf{c m}^{2}\right)$ & Friability $(\%$ w/w) & Assay $(\%)$ \\
\hline F-1 & \pm 0.85 & $5.05 \pm 0.02$ & $7.10 \pm 0.24$ & $<0.40$ & $99.85 \pm 2.50$ \\
F-2 & \pm 0.92 & $5.10 \pm 0.02$ & $7.00 \pm 0.30$ & $<0.50$ & $100.25 \pm 1.82$ \\
F-3 & \pm 1.25 & $5.20 \pm 0.03$ & $7.00 \pm 0.30$ & $<0.50$ & $101.02 \pm 1.57$ \\
F-3/H4K & \pm 0.85 & $5.20 \pm 0.04$ & $7.10 \pm 0.30$ & $<0.60$ & $99.72 \pm 0.90$ \\
F-3/H15K & \pm 2.00 & $5.20 \pm 0.03$ & $7.00 \pm 0.40$ & $<0.50$ & $100.95 \pm 1.30$ \\
F-3/4 & \pm 0.85 & $5.30 \pm 0.03$ & $4.20 \pm 0.20$ & $<0.60$ & $100.45 \pm 0.70$ \\
F-3/10 & \pm 1.35 & $5.10 \pm 0.04$ & $10.10 \pm 0.30$ & $<0.40$ & $100.83 \pm 1.47$ \\
F-4 & \pm 1.65 & $5.30 \pm 0.03$ & $7.10 \pm 0.30$ & $<0.50$ & $98.95 \pm 0.93$ \\
F-5 & \pm 1.74 & $5.30 \pm 0.04$ & $7.00 \pm 0.40$ & $<0.60$ & $99.82 \pm 2.05$ \\
\hline
\end{tabular}

Table 3: In vitro release characterizations of multi granules based controlled release tablets

\begin{tabular}{|c|c|c|c|c|c|c|}
\hline \multirow[t]{2}{*}{ Formulations } & \multicolumn{3}{|c|}{$\begin{array}{c}\text { Korsmeyer-Peppas } \\
\text { model }\end{array}$} & \multirow[t]{2}{*}{$\begin{array}{l}\text { MDT } \\
\text { (h) }\end{array}$} & \multirow[t]{2}{*}{$\begin{array}{l}\text { T50\% } \\
\text { (h) }\end{array}$} & \multirow[t]{2}{*}{$\begin{array}{l}\text { T80\% } \\
\text { (h) }\end{array}$} \\
\hline & $R^{2}$ & $K\left(\% \mathrm{~h}^{-\mathrm{n}}\right)$ & $n$ & & & \\
\hline $\mathrm{F}-1$ & 0.9869 & 32.25 & 0.39 & 4.88 & 3.11 & 10.51 \\
\hline $\mathrm{F}-2$ & 0.9937 & 26.66 & 0.44 & 5.94 & 4.31 & 11.56 \\
\hline F-2 (predicted) & - & - & - & 4.45 & 11.33 & 11.33 \\
\hline $\mathrm{F}-3$ & 0.9957 & 21.80 & 0.49 & 7.02 & 5.33 & 13.73 \\
\hline $\mathrm{F}-3 / \mathrm{H} 4 \mathrm{~K}$ & 0.9999 & 58.68 & 0.30 & 1.55 & 0.58 & 2.83 \\
\hline $\mathrm{F}-3 / \mathrm{H} 15 \mathrm{~K}$ & 0.9854 & 36.83 & 0.39 & 3.68 & 2.21 & 7.46 \\
\hline$F-3 / 4.0$ & 0.9990 & 27.35 & 0.53 & 4.10 & 3.14 & 7.67 \\
\hline$F-3 / 10.0$ & 0.9838 & 16.06 & 0.56 & 7.26 & 7.59 & 17.56 \\
\hline $\mathrm{F}-3 / \mathrm{pH} 6.8$ & 0.9902 & 22.78 & 0.48 & 6.84 & 5.09 & 13.46 \\
\hline F-3/rpm 100 & 0.9922 & 29.51 & 0.42 & 5.26 & 3.47 & 10.50 \\
\hline F-3/rpm 150 & 0.9985 & 35.34 & 0.42 & 3.54 & 2.27 & 6.86 \\
\hline $\mathrm{F}-4$ & 0.9988 & 17.64 & 0.54 & 8.31 & 6.77 & 16.03 \\
\hline F-4 (predicted) & - & - & - & 7.80 & 6.54 & 15.96 \\
\hline $\mathrm{F}-5$ & 0.9990 & 14.14 & 0.57 & 8.95 & 9.11 & 20.72 \\
\hline
\end{tabular}

MDT: Mean dissolution time, T50\%: Time of $50 \%$, T $80 \%$ : Time of $80 \%$

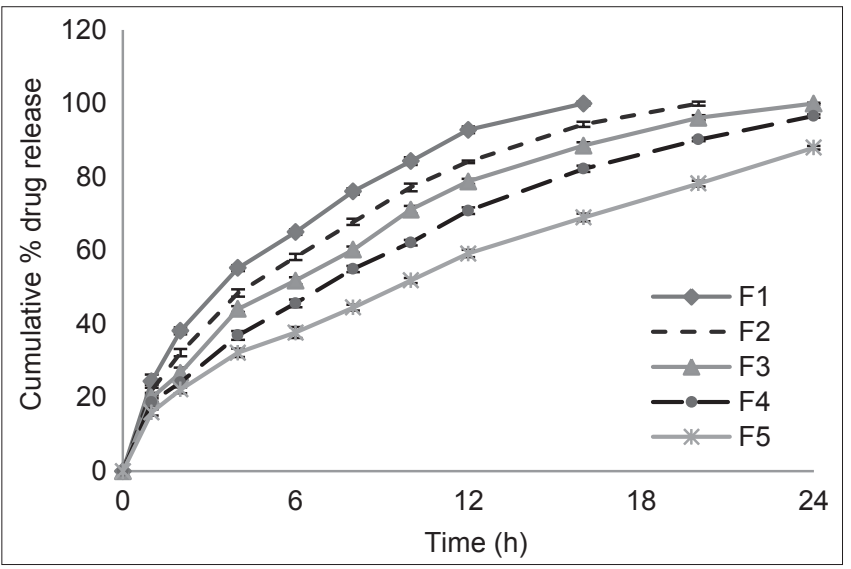

Figure 1: Comparative in vitro release profile of milnacipran from multi granules based controlled release tablets containing varying proportions of hydrophilic polymeric and hydrophobic wax granules. Each data point represents the mean of 6 tablets from three batches with standard deviation

erosion on the mechanism of drug release increased with increase in hydrophobic wax proportion. ${ }^{9}$ The MDT, $\mathrm{T} 50 \%$ and $\mathrm{T} 80 \%$ increased from $4.88-8.95 \mathrm{~h} ; 3.11-9.11 \mathrm{~h}$ and $10.51-20.72 \mathrm{~h}$ respectively as hydrophobic content increased from 0 to $100 \%$ in formulations (Table 3).
All the dissolution parameters indicated that hydrophobic wax proportion is playing a major role in controlling the drug release. The release of MIL from the combinations get more retarded than that of alone hydrophilic content, it may be due to higher lipophilicity offered by combination of waxes. ${ }^{10}$ This may be due to the slower penetration of dissolution medium in matrices due to increased liophilicity of matrix. ${ }^{17}$ Further, penetration of solvent molecule was hindered due to formation of gel layer of hydrophilic part leading to the slow percolation of drug for a prolonged period. ${ }^{18}$

\section{Effect of viscosity of hydrophilic granules}

The effect of polymer viscosity on drug release was studied with formulation F-3 containing 50\% proportion of HPMC hydrophilic granules and $50 \%$ of hydrophobic wax granules. Three formulations containing constant portion of HPMC, but different viscosity grades $4 \mathrm{~K}, 15 \mathrm{~K}$ and $100 \mathrm{~K}$ were evaluated for in vitro release behavior. Plot of per cent cumulative release versus time for various grade of HPMC are shown in Figure 2.

As the viscosity of HPMC was increased from $4 \mathrm{~K}$ to $100 \mathrm{~K}$ the release rate extended from $6 \mathrm{~h}$ to $24 \mathrm{~h}$ as shown in Figure 2. The release rate constant of KorsmeyerPeppas model was found to be $58.68 \mathrm{~h}^{-0.30}, 36.83 \mathrm{~h}^{-0.39}$ and $21.80 \mathrm{~h}^{-0.49}$ for formulations containing $4 \mathrm{~K}, 15 \mathrm{~K}$ and $100 \mathrm{~K}$ respectively. The release rate decreased as viscosity of polymer increased. The MDT, T50\% and T $80 \%$ also extended from 1.55-7.02 h; 0.58-5.33 h and 2.83-13.73 h respectively as shown in Table 3 . The $f_{2}$ (similarity factor) were found to be 18.10 (for HPMC 4K vs. 100K) and 34.30 (for HPMC $15 \mathrm{~K}$ vs. $100 \mathrm{~K}$ ) also indicated the viscosity of polymer significantly influence the drug release from designed formulations.

The release rate was faster with lower viscosity grades of HPMC. The possible explanation can be as follows. It has been reported that at the same polymer concentration, a polymer of higher viscosity (high molecular weight) induces greater chain entanglement than a polymer of low viscosity. 


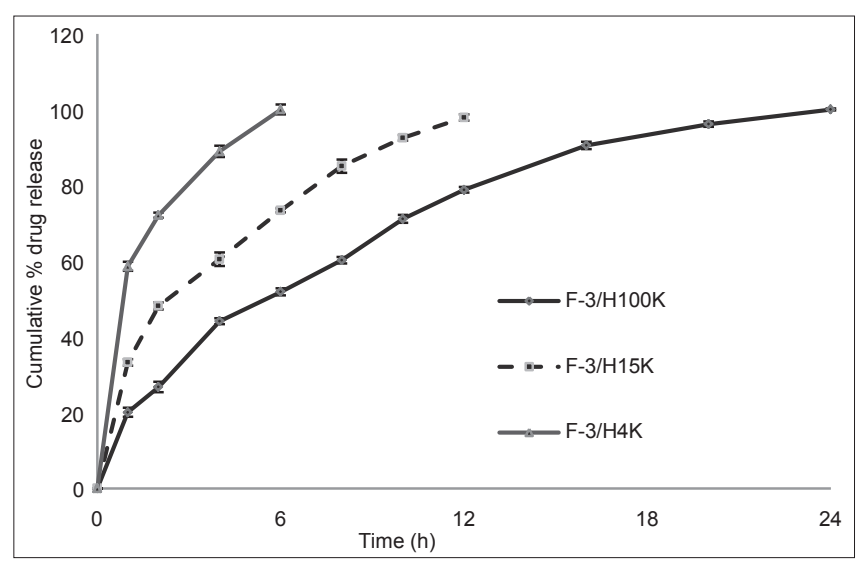

Figure 2: Effect of viscosity of HPMC polymer on milnacipran release from multi-granules based controlled release tablets. Each data point represents the mean of 6 tablets from three batches with standard deviation

Therefore, it is harder for longer chains to dissolve because of the high energy required for pulling them off the matrix. Thus, higher viscosity polymers induce the formation of a thicker gel layer after hydration lead to more retarded drug release than lower viscosity grade polymers. ${ }^{19}$

\section{Effect of compression force}

The effect of compression force on the drug release was studied with F-3 formulation compressed at different compression forces to get tablets with different hardness levels, 4,7 and $10 \mathrm{~kg} / \mathrm{cm}^{2}$. The release of the drug from formulations compressed at low compression force $\left(4 \mathrm{~kg} / \mathrm{cm}^{2}\right)$ was found to be significantly much faster with $K$ value $27.35 \mathrm{~h}^{-0.527}$ than formulation compressed at higher compression force with $K$ value $21.80 \mathrm{~h}^{-0.496}$ (for $7-7.5 \mathrm{~kg} / \mathrm{cm}^{2}$ ) and $16.06 \mathrm{~h}^{-0.560}$ (for $10-10.50 \mathrm{~kg} / \mathrm{cm}^{2}$ ). The MDT, T50\% and T $80 \%$ values increased from 4.10-7.26 $\mathrm{h}$; 3.14-7.59 $\mathrm{h}$ and 7.67-17.56 $\mathrm{h}$ respectively as compression force increased from 4 to $10 \mathrm{~kg} / \mathrm{cm}^{2}$ (Table 3 ). The $f_{2}$ (similarity factor) were found to be 40.82 for release profiles 4 versus $7 \mathrm{~kg} / \mathrm{cm}^{2}$ and 49.43 for 7 versus $10 \mathrm{~kg} / \mathrm{cm}^{2}$ indicated the compression force significantly influence the drug release from formulations.

The drug release was found to be faster at lower compression forces than at higher ones because of the relatively larger matrix porosity of the tablet, which allowed greater penetration of dissolution fluid into the matrix, thus enhancing polymer disentanglement and drug dissolution. ${ }^{18,20}$

\section{Effect of $\mathrm{pH}$ of dissolution medium}

The effect of $\mathrm{pH}$ of dissolution media on the drug release was performed with F-3 formulation in $\mathrm{pH} 1.2$ and 6.8 disso medium at $50 \mathrm{rpm}$. Drug release pattern indicated that there was no significant difference observed in release profile at $\mathrm{pH} 1.2$ and 6.8 buffer. The release rate constants Journal of Young Pharmacists Vol 6 • Issue 3 • Jul-Sep 2014 were found to be $21.80 \mathrm{~h}^{-0.496}$ in $\mathrm{pH} 1.2$ and $22.78 \mathrm{~h}^{-0.483}$ for $\mathrm{pH} 6.8$ dissolution media (Table 3). The $f_{2}$ (similarity factor) value was found to be 86.65 indicated the similarity of release profile in different dissolution medium.

This is because MIL is highly soluble at $\mathrm{pH}$ range 1.2-12, which shows its $\mathrm{pH}$ independent solubility. The hydrophobic waxes are water insoluble and having $\mathrm{pH}$ independent dissolution. The hydrophilic part consists of HPMC, a cellulose derivative with methoxyl and hydroxypropyl substituents on a $\beta$-o-glucopyranosyl ring backbone, is very resistant to changes in $\mathrm{pH}$ or ionic content of the medium. At $\mathrm{pH}$ values from 2 to 13 , HPMC is relatively stable. ${ }^{19,20}$

\section{Effect of agitation speed}

For study the effect of agitation speed, dissolution of F-3 formulation was performed at three different stirring speed 50, 100 and 150 paddle rpm. As the rpm increased from 50 to 150 the release rate decreased as shown in Figure 3. The release rate constant increased from $32.38 \mathrm{~h}^{-0.35}$ to $41.25 \mathrm{~h}^{-0.34}$ as stirring speed increased from 50 to $150 \mathrm{rpm}$. When agitation speed or paddle rpm increased 50-150, the MDT, T50\% and T $80 \%$ decreased from 7.02-3.54 h; 5.33-2.27 and 13.74-6.86 h respectively (Table 3). The $f_{2}$ (similarity factor) were found to be 49.73 and 33.38 for release profiles between 50 versus $100 \mathrm{rpm}$ and 50 versus $150 \mathrm{rpm}$ indicated the significant difference at different rotation speed. The observed variation in release change with rpm might be due to the difference in the hydrodynamic stress around the surface of tablets undergoing dissolution. At lower rpm (50 rpm), there is slow fluid motion and formation of stable stagnant layer surrounding the tablets. This prevents the quick entry into fluid and also the release of drug out of the tablet. However as rpm increased (100 and $150 \mathrm{rpm}$ ) there was greater fluid flow that resulted in increased attrition of the tablet matrix with fluid and disturbs the stagnant layer around the tablets. This caused in higher drug release. ${ }^{18,20}$

\section{Prediction of in vitro profile of developed formulation}

The predicted plasma profiles obtained from in vitro release data of F-4 CR formulation and IR formulation of equal dose using simple numerical convolution method are shown in Figure 4. These predicted plasma drug concentrations were used to determine various PK parameters from WinNonlin software using non-compartment modeling as shown in Table 4. The $\mathrm{C}_{\max }$ and $\mathrm{AUC}_{(0-t)}$ values calculated from the predicted plasma profiles of the IR tablets and CR tablets were found to be 210.86; $1 \mathrm{~h}$ and $93.46 \mathrm{ng} / \mathrm{mL} ; 12 \mathrm{~h}$ respectively. The differences between the two formulations for $\mathrm{C}_{\max }$ and $\mathrm{T}_{\max }$ were statistically significant $(P<0.05)$, 


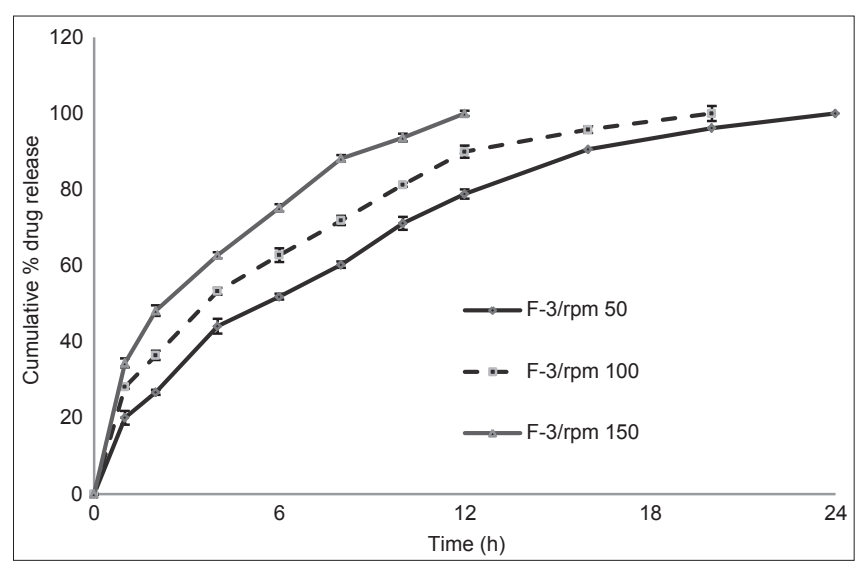

Figure 3: Effect of agitation speed on milnacipran release from multigranules based controlled release tablets. Each data point represents the mean of 6 tablets from three batches with standard deviation

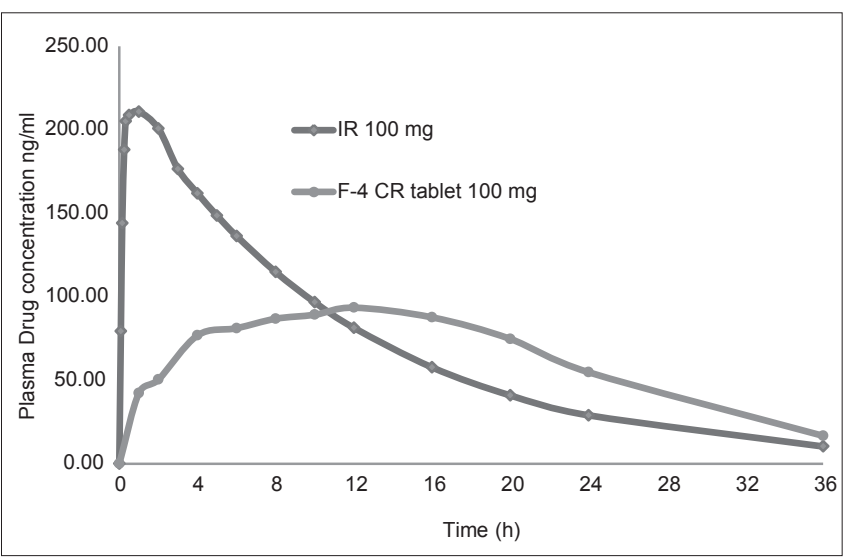

Figure 4: Predicted in vitro plasma drug concentration - time profile of immediate release (IR $100 \mathrm{mg}$ ) and controlled release (F-4 CR $100 \mathrm{mg}$ ) formulations of milnacipran

Table 4: Predicted pharmacokinetic parameters of immediate release and controlled release formulations of milnacipran using in vitro dissolution data

\begin{tabular}{|c|c|c|c|}
\hline \multirow[t]{2}{*}{$\begin{array}{l}\text { Pharmacokinetic } \\
\text { parameters }\end{array}$} & \multicolumn{2}{|c|}{$\begin{array}{l}\text { Immediate release } \\
\text { formulations }\end{array}$} & \multirow{2}{*}{$\begin{array}{c}\text { Controlled release } \\
\text { formulation (F-4) } \\
\text { Predicted }^{*}\end{array}$} \\
\hline & Reported & Predicted* & \\
\hline Dose & $100 \mathrm{mg}$ & $100 \mathrm{mg}$ & $100 \mathrm{mg}$ \\
\hline $\mathrm{C}_{\max }(\mathrm{ng} / \mathrm{mL})$ & 209.80 & 210.86 & 93.46 \\
\hline $\mathrm{T}_{\max }(\mathrm{h})$ & 1.00 & 1.00 & 12.00 \\
\hline $\mathrm{T}_{1 / 2}(\mathrm{~h})$ & 8.20 & 8.15 & 18.00 \\
\hline$A \cup C_{(0-24)}(n g / m L / h)$ & 2280.61 & 2492.73 & 2254.54 \\
\hline$\left.A \cup C_{(0-\infty)}^{(n g / m L / h}\right)$ & 2627.84 & 2624.04 & 2903.18 \\
\hline $\operatorname{MRT}(\mathrm{h})$ & 8.26 & 8.10 & 15.09 \\
\hline
\end{tabular}

${ }^{*}$ Parameters were predicted from in-vitro dissolution data using convolution method, $C_{\max }$ : Maximum plasma concentration, $T_{\text {max }}$ : Time taken to reach maximum concentration, $\mathrm{T}_{12}$ : Elimination half-life, $\mathrm{AUC}_{(0.24)}$ : Area under the plasma drug concentration versus time curve from 0 time to $24 \mathrm{~h}$, $\mathrm{AUC}_{(0-\infty)}: \mathrm{AUC}$ from 0 time to infinite time, MRT: Mean residence time

clearly demonstrate that the designed CR formulation has capability to sustain the plasma level for sufficient time and developed tablet would be suitable to deliver highly water soluble drugs like MIL for once daily dose regimen following oral administration. Predicted PK parameters of IR formulation were compared with reported PK parameters of marketed formulation of $\mathrm{MIL}^{2}$ as shown in Table 4. No significant difference was found between predicted and reported PK data. In fact, this demonstrated the reliability of convolution analyses in predicting plasma profiles by comparing the predicted profiles with in vitro data obtained from studies in humans as well as give a reasonable degree of confidence on reliability of the designed drug delivery system.

\section{CONCLUSION}

Novel multi granule based CR tablet formulations of MIL were designed and evaluated for its in vitro release. Simplex lattice technique was applied to formulation design and selection of desire formulation with minimum trials. It was concluded that multi granules based formulation were greatly influenced by proportion of hydrophobic granules, viscosity of HPMC, agitation speed and hardness of tablets. It was also observed that the designed formulations were not influenced by $\mathrm{pH}$ of dissolution media. In vitro plasma drug level and various PK parameters were predicted from in vitro release data using convolution method confirms the sustained action of designed formulations.

\section{ACKNOWLEDGMENT}

The authors are grateful to Torrent Pharmaceuticals Limited, Ahmadabad, India, for generous gift samples of milnacipran. The authors wish to thank University Grants Commission, New Delhi, India, for funding the project. This article does not contain any studies with human and animal subjects performed by any of the authors.

\section{REFERENCES}

1. Parejiya PB, Barot BS, Patel HK, Shelat PK, Shukla AK. Development of platform technology for oral controlled delivery of highly water soluble drugs using milnacipran HCL as a model drug. Drug Deliv Lett 2012;2:35-45.

2. Boyer P, Briley M. Milnacipran, a new specific serotonin and noradrenaline reuptake inhibitor. Drugs Today (Barc) 1998;34:709-20.

3. Australian Public Assessment Report for Milnacipran. Aus. PAR Joncia Milnacipran Pierre Fabre Medicament Australia Pty Ltd.; 2012. p. 78-82.

4. Singhvi G, Shah A, Yadav N, Saha RN. Study the effect of formulation variables on drug release from hydrophilic matrix tablets of milnacipran and prediction of in vitro plasma profile. Pharm Dev Technol 2014;19:708-16.

5. Hayashi T, Kanbe H, Okada M, Suzuki M, Ikeda Y, Onuki Y, et al. Formulation study and drug release mechanism of a new theophylline sustained-release preparation. Int J Pharm 2005;304:91-101.

6. Shanawany SE. Sustained release of nitrofurantoin from inert wax matrixes. J Control Release 1993;26:11-9.

7. Maderuelo C, Zarzuelo A, Lanao JM. Critical factors in the release of drugs from sustained release hydrophilic matrices. J Control Release 2011;154:2-19.

8. Vijay J, Sahadevan J, Prabhakaran R, Gilhotra RM. Formulation and 
evaluation of cephalexin extended-release matrix tablets using hydroxy propyl methyl cellulose as rate-controlling polymer. J Young Pharm 2012;4:3-12.

9. Yonezawa $\mathrm{Y}$, Ishida $\mathrm{S}$, Sunada H. Release from or through a wax matrix system. I. Basic release properties of the wax matrix system. Chem Pharm Bull (Tokyo) 2001;49:1448-51.

10. Malamataris S, Ganderton D. Sustained release from matrix systems comprising hydrophobic and hydrophilic (gel-forming) parts. Int J Pharm 1991;70:69-75

11. Singhvi G, Kalantare P, Dhoot H, Saha RN. Spectrophotometric determination of nor-epinephrine serotonin reuptake inhibitor (SNRI) drug milnacipran in pure and in dosage forms. Asian J Chem 2013;25:3682-6.

12. Bolton S. Pharmaceutical Statistics, Practical and Clinical Application. Vol. 203. New York: Marcel Dekker; 1997. p. 439-44.

13. United States Pharmacopeial Convention. United States Pharmacopeia. $32^{\text {nd }}$ ed. Rockville: United States Pharmacopeial Convention; 2009. p. 3046.

14. Costa P, Sousa Lobo JM. Modeling and comparison of dissolution profiles.
Eur J Pharm Sci 2001;13:123-33.

15. Costa P. An alternative method to the evaluation of similarity factor in dissolution testing. Int J Pharm 2001;220:77-83.

16. Qureshi SA. In vitro-in vitro correlation (IVIVC) and determining drug concentrations in blood from dissolution testing-a simple and practical approach. Open Drug Deliv J 2010;4:38-47.

17. Hamdani J, Moës AJ, Amighi K. Development and evaluation of prolonged release pellets obtained by the melt pelletization process. Int J Pharm 2002;245:167-77.

18. Ravi PR, Kotreka UK, Saha RN. Controlled release matrix tablets of zidovudine: effect of formulation variables on the in vitro drug release kinetics. AAPS Pharm Sci Tech 2008;9:302-13.

19. Kim H, Fassihi R. Application of binary polymer system in drug release rate modulation 2. Influence of formulation variables and hydrodynamic conditions on release kinetics. J Pharm Sci 1997;86:323-8.

20. Hiremath PS, Saha RN. Controlled release hydrophilic matrix tablet formulations of isoniazid: Design and in vitro studies. AAPS Pharm Sci Tech 2008;9:1171-8. 